VENTILATORY RESPONSES TO CO2 IN PREMATURE INFANTS TH INTRAVENTRI CULAR HEMORRHAGE, Maria Fort. Francoise Marotta, Mujahid Anwar, T. Mark Hiatt. Thomas Hegyi, UMDNJ-Rutgers Medicat School, St. Peter's Medical School, Dept. of Pediatrics, New Brunswick, N. J.

No significant differences were found in the ventilatory response to $\mathrm{CO} 2$ in a group of very low birthweight infants evaluated for apnea. Twenty-two infants were divided into two groups based on the presence or absence of IVH. Group I consisted of 11 infants (BW $1050+380 \mathrm{~g}, \mathrm{GA} 28+1 \mathrm{wk}$ ), 8 suffering from Grade III, and 3 from Grade IV IVH. Ēleven infants (BW $1130+210 \mathrm{~g}$, GA $28+2 \mathrm{wk})$ comprised Group II, the control population. Group I was examined at $44+9$ weeks postconceptual age, and Group II at $42+10$ weeks $\left(\begin{array}{ll}P & 0.05\end{array}\right)$. Ventilatory response to $\mathrm{C} 02$ was measured by a computerized wave form analyzer.

The results of the study are presented below:

\begin{tabular}{lcc} 
& Group I (IVH) & Group II \\
\cline { 2 - 3 } Slope (ml/kg/min/mmHg BTPS) & $35.8+16.4$ & $33.6+16.2$ \\
Baseline PCO2 (mmHg) & $39.6+3.3$ & $40.8+5.3$ \\
Basel ine Ve (mI) & $307 \pm 144$ & $287 \pm 123$ \\
PCO2 at Ve $=300 \mathrm{ml}$ ( $\mathrm{mmHg}$ ) & 39.7 & 36.70 \\
N. aroused be fore test end & 7 & 6
\end{tabular}
N. a roused before test end$$
7
$$$$
6
$$

In the group of infants with apnea, IVH did not affect the slope or position of the $\mathrm{CO} 2$ response curve, the baseline data, nor the frequence of arousal prior to test compietion. These responses did not correlate with IVH severity. The increase incidence of apnea with IVH does not seem to be related to a compromised response to $\mathrm{CO2}$.

VENTILATORY RESPONSE TESTING IN PREMATURE INFANTS, 1393 Maria Fort, Francoise Marotta, I. Mark Hiatt, Thomas Hegyi, UMDNJ-Rutgers Medical Schoo1, St. Peter's Medical Center, Department of Pediatrics, New Brunswick, NJ. We studied the reproducibility of ventilatory response to $\mathrm{CO} 2$ in a group of premature infants with real or potential disturbances in the control of ventilation. (Ten infants BN 2.0+0.8 $\mathrm{kg}, \mathrm{GA} 35+4$ wks) comprised the test population, 6 with idiopathic apnea, 3 siblings of SIDS, and 1 near miss. The group was examined at $42+6$ wks postconceptual age with a computerized waveform analyzer providing ventilatory response data to inhaled C02. A second test was done 30 minutes after completion of the first.

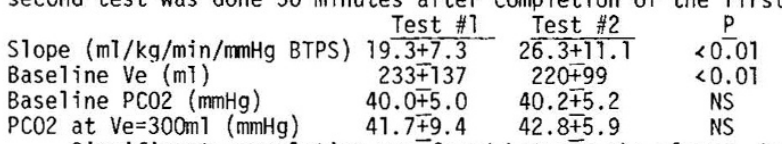
$\begin{array}{llll}\text { Baseline PC02 (mmHg) } & 40.0 \mp 5.0 & 40.2 \mp 5.2 & \text { NS } \\ \text { PCO2 at } \mathrm{Ve}=300 \mathrm{ml}(\mathrm{mmHg}) & 41.7 \pm 9.4 & 42.8+5.9 & \text { NS }\end{array}$ Significant correlation was found between the slopes, but significant differences were observed between their means $(R<0.01)$ Baseline Ve was significantly lower in the repeat test with six infants starting at a lower level. Seven infants aroused at a lower $\mathrm{PCO} 2$ in the second test but the $\mathrm{PCO} 2 \mathrm{~s}$ at arousal were not different.

It appears that the infants in this study became more sensitive to that the $\mathrm{CO2}$ challenge of the first test affected the second, and an interval greater than $30 \mathrm{~min}$. may be necessary to duplicate results.

\section{$\dagger 1394$}

DEVELOPMENT OF MECHANICAL STABILITY OF THE RESPIR(Spon, by Richard D. Bland) University of California and Cardiovascular Research Institute, San Francisco, CA. 94143 Distortion of the chest wall(CW) causes the diaphragm (DI) to make increased excursions for adequate pulmonary ventilation (PV). We studied the development of mechanical stability of the respiratory system by estimating the ventilation of the diaphragm (VD), its work (WD), and lung compliance (CL) in 6 preterm infants (wt. 780-1710g) at weekly intervals, from 29-36 post conceptional weeks (PCW) of age. Three to 5 studies were performed in each infant while in quiet sleep in room air. PV was partitioned between that produced by the CW and DT using a Respitrace inductance plethysmograph, calibrated against PV measured with a face mask and pneumotachograph, checked with airway occlusion. Esophageal and gastric pressures were measured with a modified feeding catheter.

CL increased linearly with age $(C L=0.61 \mathrm{PCW}-17.3 \mathrm{ml} / \mathrm{cm}$ $\mathrm{H}_{2} \mathrm{O} / \mathrm{kg}, \mathrm{P} .005$ ), and VD decreased with age (VD $=-14.8 \mathrm{PCW}+603$ $8^{2}$ of PV, P .005). WD and VD decreased consistently in $4 / 6$ infants. The other 2 infants developed apnea, with increased VD (1228 and 1878) and WD (2398 and 3028) compared to studies prior to apnea. Both VD and WD decreased to previous values with resolution of apnea. There was no relationship between $\mathrm{CL}$ and apnea.

These results suggest that apnea may be related to instability of the chest wall and diaphraqm, as measured by VD and WD, independent of lung stability reflected by CL.

Supported by NHLBI SCOR HL-27356 and AIA 57002
1395 ADVISABILITY OF INFFNSIVE CARE FOR VERY LOW BIRTH WETGHT (VLBW) INFANIS Michael Horgan, Michael Sonnekalb, Marc Perlman. Nick Department of Pediatrics, Albary, New York.

Controversy exists over providing intensive care to VLH infants. We examinad the effects of current intensive care on survival and nurologic outcome on 121 infants of birth weight (BW) $500-1000$ bom in 1981-82, and identified factors associated with death or poor outcome. Survivors (S) and non-survivors (NS) are characterized below: (GA=Gestation)

\begin{tabular}{|c|c|c|c|}
\hline & & $i z a d$ & $A=G e s+a$ \\
\hline $44(36 \%)$ & $000+\bar{g} *$ & CA & Days Ventilate \\
\hline is $77(64 \%)$ & $735+156$ & $25.7+1.7$ & $2.1+4.7$, \\
\hline
\end{tabular}

of 40 infants of $B W(700$ gn survived; $70 \%$ of NS were $G \bar{A}\langle 27$ wk. $56 \%$ of $S$ were delivered by C-section, compared to $28 \%$ of NS. Use of machanical ventilation, incidence of NEC, PDA did not differ between $S$ and NS. The relation of early survival to eventual survival is shown below:

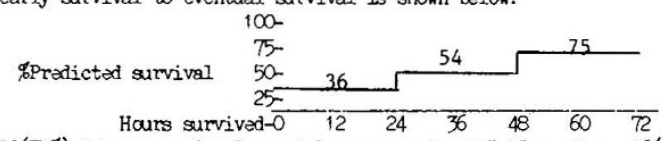

32(73\%) S had naurodevelopmental assessments at 7-15 months. 16(50\%) were normel, $7(22 \%)$ mildly abnomal, $9(28 \%)$ severely abonomal. Poor outcame was associated with Grade 3-4 IVH, prolonged ventilaion, BPD. Conclusion: Inants of $\mathrm{BW}\langle 700 \mathrm{gm}, \mathrm{GA}(27 \mathrm{wk}, 2 s p e c i a l l y$ if vaginally delivered, have remote ants of BW(700gm, GA. Whe especially if vaginally delivered, have remote chances of survival. Most deaths occur by 48 hours despite intensive care.
Infants successfully supported past 48 hours have reasonable chances of a good Infants successfully supported past 48 hours have reasonab
quality survival. Supported in part by NYS AMR-DD Grant

SSOCIATION OF PERINATAL FACTORS WITH INTRACRANIAL 1396 HEMORRHAGE (ICH) IN THE VERY LOW BIRTHWEIGHT (VLBW) PRETERM NEONATE Alastair A. Hutchison, Jeffrey $M$. Barrett, Arthur C. Fleischer, Ronald G. Thomas, A. Everette Ped., Nashville, and Univ, of Florida, Depts. of Ped. and Biostat., Gainesville.

Perinatal factors were recorded fron one hundred inborn VLBW neonates, studied consecutively. Their mean ( $+\mathrm{SE}$ ) gestational age (GA) was $29+0.4$ weeks and their mean birthweight (BWt) was $1094 \pm 45 \mathrm{~g}$. Crañial ultrasound was used to diagnose the presence and severity of ICH. The incidence of ICH was $32 \%, 18 \%$ being major and $14 \%$ minor. The mortality from ICH was $34 \%$, representing $56 \%$ of those with major and $7 \%$ of those with minor ICH. Univariate analysis showed that only premature labor (prem lab) and vaginal delivery (vag del) were significantly associated with the diagnosis of ICH. The reduced incidence of ICH associated with cesarean section was noted only if the presentation was vertex. Using stepwise logistic regression to build a model from potential risk factors, prem $1 \mathrm{ab}$, admission $\mathrm{PaCO}_{2}\left(\mathrm{AdPaCO}_{2}\right)$, potential risk factors, prem $1 \mathrm{ab}$, admission $\mathrm{PaCO}_{2}(\mathrm{AdPaCO})$,
Apgar at $1 \mathrm{~min}$ and vag del were identified as the most predictive factors for ICH. The most predictive factors in those <30 wks GA were prem $1 \mathrm{ab}$ and artificial ventilation for greater than 24 hours (IMV $>24 \mathrm{hrs}$ ), and in those $\geqslant 30$ wks were vag del, Apgar at 5 min and $\mathrm{AdPaCO}_{2}$. The occurrence of major $\mathrm{ICH}$ was predicted best by $\mathrm{GA}$, IMV $>24 \mathrm{hrs}$, and prem $1 \mathrm{ab}$. ICH in the VLBW neonate relates to the presence of prem $1 \mathrm{ab}$ and respiratory distress in the very immature neonate, while mode of delivery and early respiratory care are important in the more mature high risk preterm neonate.

T TRANSIENT HYPERAMMONEMIA OF THE NEWBORN (THAN) AND † 1397 UREA CYClE ENZYME DEFECTS (UCED) DIFFERENTIATED BY CLINICAL PRESENTATION. M.L. Hudak, M.D. Jones, Jr. and S. Brusilow. Johns Hopkins Hospita1, Baltimore, Md. 21205 THAN and UCED have been presumed to have identical clinical presentations (N. Engl. J. Med. 299:920, 1978). We reviewed clinical data on 19 patients with THAN: 5 previously unreported and 14 from the literature. Thirteen neonates with UCED within the past 5 years served for comparison. Both obstetrical and neonatal data were analyzed by $X$-square and Student's $t$ tests. No differences were found in the route of delivery, perinatal complications, Apgar score, sex, or in incidence or time of onset of seizures. On the other hand, neonates with THAN had significantly lower birth weights $(2255 \pm 97$ vs $3335 \pm 222 \mathrm{~g}, \mathrm{p}<.001, \mathrm{X} \pm$ SEM $)$ and gestational ages $(34.4 \pm 0.5$ vs $39.6 \pm 0.6$ wks, $p<.001)$. Onset of respiratory distress $(3.5 \pm 1.6$ vs $70 \pm 26.4 \mathrm{~h}, \mathrm{p}<.01)$, ventilatory support $(26.1 \pm 5.2$ vs $79.4 \pm 11.9 \mathrm{~h}, \mathrm{p}<001)$, lethargy $(25.5 \pm 4.7 \mathrm{vs}$ $77.3 \pm 17.0 \mathrm{~h}, \mathrm{p}<.01)$ and coma $(41.7 \pm 5.9$ vs $97.5 \pm 16.7 \mathrm{~h}, \mathrm{p}<.01)$ occurred earlier in THAN. Significant distinguishing laboratory features in THAN included more frequently abnormal chest $x$-rays $(10 / 12$ vs $0 / 9, p<.001)$ and initial serum ammonia levels that were higher $(3049 \pm 483$ vs $1745 \pm 287 \mu \mathrm{g} / \mathrm{d} 1, p<.05)$ at an earlier age $(55.5$ \pm 7.2 vs $124.6 \pm 22.3 \mathrm{~h}, \mathrm{p}<.01)$. Seventeen patients with THAN and all patients with UCED could be scored on at least 4 of these 7 criteria: birth weight $\leq 2500 \mathrm{~g}$, gestational age $\leq 36$ wks, respiratory distress $\leq 12 \mathrm{~h}$, lethargy $\leq 36 \mathrm{~h}$, coma $\leq 48 \mathrm{~h}$, abnormal CXR, and initial $\left(\mathrm{NH}_{3}\right)>1500 \mu \mathrm{g} / \mathrm{dl}$. $\overline{\mathrm{A}} 11 \mathrm{16}$ patients with total score iates THAit from UCED. 